about formal curriculum change which he did not address. In Britain, over the last twenty years, traditional anatomy teaching and dissection time have been greatly squeezed by the demands of new preclinical subjects and knowledge and for more clinical integration. In doing this, has sufficient attention been paid to the latent functions of traditional anatomy in helping students learning to cope with death?

MARY ANN ELSTON, Dept of Social Policy and Social Science, Royal Holloway and Bedford New College, University of London.

\title{
Child psychiatry and the law: second edition
}

\begin{abstract}
Edited by Dora Black, Stephen Wolkind and Jean Harris Hendriks, London, Gaskell, 1991, 200 pages, $£ 10.00$
\end{abstract}

Child psychiatrists spend a good deal of time in court. This is not, as a rule, because of their criminal behaviour, but because they are now quite frequently asked to provide an opinion for the benefit of magistrates and judges on decisions affecting the welfare of children.

The fitness of parents who may be suffering from mental illness or personality disorders to look after their children; disputes over, whether, for example, a separated father should have rights of contact when the child is living with mother; the placement of disturbed, delinquent children, nonattendance at school - these are all issues on which child psychiatrists are expected to pronounce.

Their views may be sought because the child in question lives in their locality and they have had previous contact with the family. Alternatively they may be asked to give an opinion as expert witnesses.

The furnishing of evidence in these situations has raised a number of ethical dilemmas in the past. Many of these have been, at least to some degree resolved, partly by changes in legislation (1989 Children Act) and partly by changes in professional practice.

In the light of the Act, professionals are expected to act in partnership with parents, so that psychiatrists have to take into account the willingness of parents, for example, for their children to receive psychological treatments, as well as their own view of the child's needs. Not so long ago, a child psychiatrist was accused by a judge as acting as a 'paid hack' when he gave evidence for one party in a custody dispute.

Now it is recognised that, no matter which solicitor instructs them, child psychiatrists give an opinion based on the child's welfare needs. Most, if not all, child psychiatrists would refuse to provide an opinion unless this was understood from the outset.

The book is written primarily as a guide for child psychiatrists asked to give evidence in these circumstances. It provides an excellent account with the helpful inclusion of a number of specimen reports. No child psychiatrist should be without it. It would be of somewhat less interest to other professionals. The book would be of interest to social workers, probation officers, magistrates, judges, and indeed anyone with an interest in the interface between law and psychiatry.

PHILIP GRAHAM, Behavioural Sciences Unit, Institute of Child Health,

London.

\section{The greening of medicine}

\section{Patrick Pietroni, London, Gollancz, 1991, 227 pages, pb $£ 6.99$}

Bioethics literature is peppered with appeals to Kuhnian theory in support of agendas which allegedly call for different perspectives on an issue. But conceptual revolutions are infrequent events in the history of ideas.

Consistent with the popular dependence on the idea of the paradigm shift is Patrick Pietroni's The Greening of Medicine. This book argues that orthodox medicine has trenchantly resisted the messages of green consciousness, but also that there is some early evidence of assimilation. The author is a western-trained practitioner who is in the forefront of incorporating a number of green ideas into daily medical practice in the UK.

According to Pietroni, an enlightened medicine will draw from ideas of interconnectedness, homeostasis, ecology and wholeness, based in new world views such as general systems theory and holism. Orthodox medicine and its biomedical model follow the reductionist pattern of mastery over nature without the accountability which should accompany it. Green consciousness, emphasising interconnectedness, is necessary to re-instil that accountability. Pietroni produces a balanced view of the roles of reductionist and green insights, though I believe the balance is a superficial one.

New Age rejections of the insights of the Age of Reason are dismissed. 'One can be holistic and suggest brain surgery', for example. So holistic medicine should be an integration of technical capabilities with more recent ones derived from psychology, politics, anthropology and consumerism. A familiar trend emerges: from treating patients as repeatable Newtonian systems to a practice responsive to all the detail and interrelationship of this patient in this situation.

Many criticisms are valid as they stand. Drug therapy can be utopian, and tend to neglect side-effects and interactions. Its industry-driven nature calls for critical surveillance. The author baulks at endorsing Illich's rather inflammatory view that the loss of traditional virtues such as endurance through suffering constitutes evidence of a malign anti-human iatrogenesis at work. More accurately, he contends, there has been a public/ patient/profession collusion, rooted in universal human drives and consumerism, which has led to a prescribing blow-out and demands for quick fixes.

Pietroni is on thinner conceptual ground when urging the falsity of the view that medical diagnosis is premissed on notions of value-free science and inductive reasoning. His accurate observation that most clinicians employ a hypotheticodeductive model, and rely on discriminative questions to test a hypothesis, cannot obscure the fact that these habits themselves build on agreed understandings of pathological processes, arrived at through observation, measurement and induction. Pietroni makes overly simple connections between questions about objectivity in recent philosophy of science and everyday practice which does importantly stand on agreed objective data.

The risk, of course, is to throw out the baby with the bathwater, something which was to be avoided by taking an integrated approach. We are told that: 
"The development of "high tech" medicine which follows this fascination for precision and excellence has led to the development of medical care that still remains unchallenged. Comparative large scale random surveys comparing the benefits to patients with coronaries nursed in intensive care units and at home have shown no difference in morbidity or mortality.' (Page 47)

But he fails to acknowledge that claims about relative effectiveness stand or fall on the application of science's strict criteria of validity. This blindness occurs throughout the book. While surveys and trials are appealed to repeatedly, the book urges us to suspend our allegiance to notions of causality, in favour of the distinct relation of connectedness.

One of the significant aspects of the greening process has been the erosion of physicians' status and power. We are given a straightforward account of this development, based in the proletarianisation of knowledge, consumerism, the rise of ancillary professions, and increasing incursions by the state in the doctor/patient relationship. Now these factors are said to have contributed to the erosion of professional power. Since we are not provided with an account of what it is for one or several things to contribute to another, we could be forgiven for thinking that Pietroni means that these factors have caused the erosion. Again, the notion to be superseded by the new epistemological paradigm is employed in explicating the desired shift.

That government intrusion is not so much a green strategy as a cost-driven pragmatic strategy is not lost on Pietroni. He remains open as to whether the bureaucratisation process will be ultimately beneficial to patients. Perhaps he shares some of the demoralisation he sees in the profession as a whole.

In the second half of the book, the dawning influence of green ideas on practice is described. The utopian drive to fight and deny death is slowly being softened through bereavement counselling, palliative care, and the hospice movement. Cancer is often managed in a less aggressive way, incorporating a wider range of expertise than the traditional modalities. Psychiatry has seen extensive revision of its models with divergences away from the biophysical to more egalitarian approaches such as humanistic psychology. The author mentions the excesses some of these endeavours have been associated with, like the false promises of pop psychology and new age self-actualisation. A further insight is to bring out the illegitimacy of the move to equate a number of alternative therapies with green medicine because of the difficulty of assessing the value of alternatives. But, to labour the point, what will be the methodology of such assessment?

Attendance at alternative practices allegedly reflects the failure of orthodox medicine to address problems of the spirit. Pietroni describes three practical attempts in the UK, including his owr. Marylebone health centre, where the aim is to reinstate the spiritual, and to support the values of knowledge and power-sharing, selfhelp and responsibility. Green GPs are seen as latter-day priests offering safety, warmth, active listening, and compassionate touch. All this is not surprising in an age in which empiricism has not left much of a religious sense to sustain us through life's interpersonal and existential struggles. Green ideas are an attempt to help us work out our relations to ourselves and the physical world, given that many have ceased to ponder relations with any deity. But most of us are, in a generic sense at least, religious; perhaps this is why medicine is expected to help us find our way back to the spirit. The question is whether medicine alone can answer such a need, or whether that is asking too much. Will a holistic medical enterprise, critical of the limits of traditional medicine, and purporting to empower people with knowledge and technique to make their lives optimally healthy, be ultimately unaffordable?

Green and inclusive medicine will still be asked to justify itself. Accountability to the values espoused by green consciousness would seem to depend on the tradition of measurement and validation, not on eschewing that tradition. While it provides us with numerous insights into the changes occurring in medical practice, Pietroni's boo fudges the provision of a coherent account of the relation of connected ness, which is claimed to be a new way of conceiving medical practice. If connectedness does not collapse into causality, perhaps its elusiveness will spawn a far more insatiable utopianism than it is designed to supplant.

MALCOLM PARKER General Practitioner, and Visiting Lecturer in Humanities, Queensland University of Technology, Brisbane, Australia. 